\title{
Effects of feeding medium-chain triacylglycerols on maternal lipid metabolism and pup growth in lactating rats
}

\author{
BY PAULO F. A. SOUZA* AND DERMOT H. WILLIAMSON† \\ Metabolic Research Laboratory, Nuffield Department of Clinical Medicine, Radcliffe Infirmary, \\ Woodstock Road, Oxford OX2 $6 \mathrm{HE}$
}

(Received 13 March 1992-Accepted 5 August 1992)

\begin{abstract}
To study the effects of medium-chain triacylglycerols (MCT) on maternal lipid metabolism and pup growth, MCT $(200 \mathrm{~g} / \mathrm{kg})$ were incorporated into a commercial chow diet and fed to lactating rats for 8-10 d. The results were compared with similar diets containing sunflower oil (polyunsaturated fatty acids; PUFA), tristearin (saturated fatty acid) or triolein (monounsaturated fatty acid). There was decreased food and energy intake with the MCT diet and this was accompanied by decreased (35\%) pup growth. All the high-fat diets inhibited lipogenesis in vivo in the lactating mammary gland, the order of effectiveness being PUFA $>$ triolein $>$ tristearin $>$ MCT. Only the MCT diet increased the rate of hepatic lipogenesis $(180 \%)$. Experiments feeding an MCT meal containing $\left[1-{ }^{14} \mathrm{C}\right]$ octanoate indicated that very little $(3-4 \%)$ of the $\mathrm{C}$ was present in mammary gland lipid, unlike the findings with $\left[1-{ }^{14} \mathrm{C}\right]$ triolein meal $(40 \%)$. The major portion $(65 \%)$ of the absorbed $\left[1-{ }^{14} \mathrm{C}\right]$ octanoate was oxidized to ${ }^{14} \mathrm{CO}_{2}$. There was no evidence for adaptation of the mammary gland to increased dietary lipid uptake on the triolein or MCT diets. It is concluded that the decreased pup growth on the MCT diet is due in part to the decreased energy intake and to the inability of dietary medium-chain fatty acids to provide substrates for milk lipid synthesis.
\end{abstract}

Medium-chain triacylglycerols: Lactation: Rats

Milk lipid supplies about $50 \%$ of the energy intake of the breast-fed baby and alteration in the amount of lipid consumed may have profound effects on postnatal development. It is derived from two sources: (a) de novo synthesis (lipogenesis) of fatty acids within the mammary gland and their subsequent esterification to triacylglycerols; $(b)$ uptake of preformed lipid from the plasma by the lactating mammary gland (for review, see Bauman \& Davis, 1974). This latter may be in the form of non-esterified fatty acids (NEFA) derived from the hydrolysis of triacylglycerols stored in adipose tissue or triacylglycerols (chylomicrons or very-low-density lipoproteins (VLDL)). Chylomicrons are lipid-rich lipoproteins secreted by the intestine into the peripheral circulation and the lipid component is mainly from the diet (for review, see Tso \& Balint, 1986). VLDL are secreted from the liver and the lipid moiety may arise from de novo synthesis and/or NEFA originally released from adipose tissue (for review, see Gibbons, 1990). The major precursor for lipogenesis in lactating mammary gland of the rat is glucose (Katz et al. 1974; Robinson \& Williamson, 1977) and the main products are medium-chain fatty acids (Libertini \& Smith, 1978) which are esterified to milk medium-chain triacylglycerols.

The fate of dietary medium-chain triacylglycerols $\left(\mathrm{MCT} ; \mathrm{C}_{6}-\mathrm{C}_{10}\right.$ ) is different to that of the long-chain triacylglycerols (LCT; $\mathrm{C}_{12}-\mathrm{C}_{24}$; Greenberger \& Silkman, 1969; Bach \& Babayan, 1982). The medium-chain fatty acids released from dietary MCT are not re-

* Present address: Laboratório de Bioquímica da Nutriçao, Departamento de Nutriçao, Faculdade de Saúde, Universidade de Brasília, Campus Universitário, Brasília-DF 70.000, Brasil.

$\dagger$ For reprints. 
esterified in intestinal cells and are transported directly via the portal blood to liver for partial oxidation to ketone bodies or complete oxidation to $\mathrm{CO}_{2}$ (Greenberger \& Silkman, 1969). Consequently, dietary MCT are more readily utilized for energy than LCT, and less effectively incorporated into adipose tissue triacylglycerols (Baba et al. 1982; Geliebter et al. 1983).

Previous work has shown that administration of an oral load of either LCT or MCT to lactating rats acutely inhibits the rate of lipogenesis in vivo in the mammary gland and that this inhibition is partly reversed by injection of insulin (Agius \& Williamson, 1980). Recent in vitro experiments with rat mammary gland secretory cells have shown that certain medium-chain fatty acids (hexanoate, $\mathrm{C}_{6}$; octanoate, $\mathrm{C}_{8}$; decanoate, $\mathrm{C}_{10}$ ) inhibit the conversion of glucose to lipid; laurate, $C_{12}$, had no effect (Heesom et al. 1992).

The present study was designed to answer the following questions: (a) Does feeding a chow diet containing increased amounts of MCT affect lipogenesis in mammary gland and liver of lactating rats? $(b)$ Is there evidence for increased uptake of MCT-C into mammary gland after a period of feeding a diet high in MCT? (c) What are the effects of this diet on pup growth? Diets containing the same amount of saturated or unsaturated LCT were used for comparison. The findings have been reported in a preliminary form (Souza \& Williamson, 1990, 1991).

\section{MATERIAL AND METHODS}

\section{Rats}

Lactating Wistar rats (250-350 g; 1st lactation) were fed ad lib., except where stated, with free access to drinking water. They were maintained at an ambient temperature of $22 \pm 2^{\circ}$ with a $12 \mathrm{~h}$ light-dark cycle (lights on from 07.00 hours). All experimental procedures were commenced between 09.00 and 10.00 hours, unless otherwise stated. Food intake, maternal body weight and litter weight were monitored every second day. The number of pups was maintained at ten per litter.

\section{Chemicals}

All enzymes and biochemicals were obtained from Boehringer Corp. (London) Ltd, Lewes, Sussex. $\left[1-{ }^{14} \mathrm{C}\right]$ Triolein, $\left[1-{ }^{14} \mathrm{C}\right]$ octanoate and ${ }^{3} \mathrm{H}_{2} \mathrm{O}$ were obtained from Amersham International, Amersham, Bucks.

\section{Diets}

The control diet was a commercial chow diet composed of $(\mathrm{g} / \mathrm{kg})$ carbohydrate 520 , protein 210 , fat 40 and a residue of non-digestible material (Special Diet Services, Witham, Essex). The high-fat diets were prepared by increasing the amount of fat in the chow diet to $200 \mathrm{~g} / \mathrm{kg}$ by weight. The commercial diet was ground to a powder, the appropriate fat was added and the mixture reconstituted to the pelleted form with a little water. The pellets were dried at room temperature to constant weight. The following high-fat diets were used: $(a)$ saturated (tristearin, glycerol tristearate; Sigma); $(b)$ polyunsaturated (PUFA, sunflower oil high in polyunsaturated fats; Sainsbury plc, Trowbridge, Wilts.); (c) monounsaturated (triolein, $61 \%$; Sigma); $(d)$ medium-chain triacylglycerols $\left(\mathrm{MCT}\right.$, consisting of $(\mathrm{g} / \mathrm{kg}) \mathrm{C}_{6}$ $20, \mathrm{C}_{8} 560, \mathrm{C}_{10} 400$ and $\mathrm{C}_{12} 15$; MCT oil; Cow \& Gate plc). The fat content of each diet was determined by lipid extraction and gravimetric analysis. Lactating rats were offered one of the experimental diets or the chow diet (fat content $40 \mathrm{~g} / \mathrm{kg}$ ) $2 \mathrm{~d}$ after parturition and were kept on the diet for $8-10 \mathrm{~d}$. This period was chosen because most metabolic studies have been carried out at mid-lactation (10-12 d).

\section{Measurements of lipogenesis}

The rate of lipogenesis in vivo was determined with ${ }^{3} \mathrm{H}_{2} \mathrm{O}$ as previously described (Robinson et al. 1978). Rats were injected intraperitoneally with $0.3 \mathrm{ml}(10 \mathrm{mCi} / \mathrm{ml}){ }^{3} \mathrm{H}_{2} \mathrm{O}$ and $55 \mathrm{~min}$ 
later they were anaesthetized with pentobarbital $(60 \mathrm{mg} / \mathrm{kg}$ body weight; $60 \mathrm{~g} / 1 \mathrm{in}$ distilled water). At 60 min after injection of ${ }^{3} \mathrm{H}_{2} \mathrm{O}$, venous blood (epigastric vein) was collected from the mammary gland and arterial blood from the abdominal aorta. Duplicate weighed samples were taken of liver, parametrial adipose tissue and inguinal mammary gland and a single sample of brown adipose tissue. The tissues were saponified, fatty acids extracted by the method of Stansbie et al. (1976) and the radioactivity in the lipid fraction measured.

\section{Measurements of disposal of ${ }^{14} \mathrm{C}$-labelled lipid in meal}

The measurement of the absorption, oxidation to ${ }^{14} \mathrm{CO}_{2}$ and tissue lipid accumulation of the dietary ${ }^{14} \mathrm{C}$-labelled lipid was essentially as described by Oller do Nascimento \& Williamson (1986). The rats were starved for $24 \mathrm{~h}$ and then offered $5 \mathrm{~g}$ of the chow diets containing ${ }^{14} \mathrm{C}$-labelled lipid; this amount of diet was usually consumed within $20 \mathrm{~min}$. The rats were then placed in individual desiccators with their pups. Expired ${ }^{14} \mathrm{CO}_{2}$ was collected in Lumasorb (25 ml; May \& Baker, Dagenham, Essex) and the absorbent was renewed hourly for $5 \mathrm{~h}$. At the end of this period the rats were anaesthetized, tissues collected and lipid extracted (see pp. 780-781). Absorption of lipid was calculated by subtraction of radioactivity remaining in the gastrointestinal tract from that contained in the $5 \mathrm{~g}$ meal. Tissue lipid accumulation is expressed as percentage of absorbed dose to correct for interindividual variations in absorption.

\section{Determination of blood metabolites}

Whole blood was collected into heparinized syringes and deproteinized with $\mathrm{HClO}_{4}$ $(6 \mathrm{~g} / \mathrm{l})$. Metabolites were determined on the neutralized, deproteinized extracts (Mercer \& Williamson, 1987). Standard enzymic methods were used for glucose (Slein, 1963) and lactate (Hohorst, 1963).

\section{Statistics}

The results are mean values with their standard errors with the number of individual observations indicated. Statistical significance was determined by Student's $t$ test with additional Bonferroni correction where multiple comparisons were involved (Wallenstein et al. 1980).

\section{RESULTS AND DISCUSSION}

Food and energy intake and pup growth

The rats fed on the tristearin (saturated) diet had significantly higher energy intake than those fed on chow, whereas those fed on triolein (monounsaturated) or MCT diet had a lower food intake (18 and 33\% respectively) and in the latter case lower energy intake $(12 \%$; Table 1). The higher energy intake by the rats fed on tristearin may be linked to the poor absorption of stearate (Hamilton et al. 1969; P. F. A. Souza \& D. H. Williamson, unpublished results).

The low intake of the MCT diet might be due to decreased palatability or delayed gastric emptying; however, these possibilities seem unlikely because there was no delay compared with the chow diet in the time taken for eating a meal of MCT or its rate of absorption (results not shown). An alternative explanation is that the medium-chain fatty acids derived from the MCT diet are rapidly extracted and oxidized by the liver and the resulting increase in hepatic energy state and plasma ketone bodies may act as a signal to decrease food intake (Scharrer \& Langhans, 1990).

The MCT diet decreased the gain in pup weight by $35 \%$ compared with the chow diet, whereas the other high-fat diets had no significant effect on pup growth (Table 1). Grigor \& Warren (1980) observed that feeding lactating rats for $4 \mathrm{~d}$ on a synthetic diet containing coconut oil $\left(200 \mathrm{~g} / \mathrm{kg}\right.$ diet; $490 \mathrm{~g}$ lauric acid $\left(\mathrm{C}_{12}\right) / \mathrm{kg}$ oil $)$ did not affect weight gain of the 
Table 1. Diet and energy intake, and pup growth in lactating rats fed on high-fat diets for $8 d \dagger$

(Mean values with their standard errors)

\begin{tabular}{|c|c|c|c|c|c|c|c|}
\hline \multirow[b]{2}{*}{ Diet } & \multirow[b]{2}{*}{$n$} & \multicolumn{2}{|c|}{$\begin{array}{l}\text { Diet intake } \\
(\mathrm{g} / \mathrm{d})\end{array}$} & \multicolumn{2}{|c|}{$\begin{array}{l}\text { Energy intake } \\
(\mathrm{kJ} / \mathrm{d})\end{array}$} & \multicolumn{2}{|c|}{$\begin{array}{l}\text { Pup growth } \\
\text { (g/d per pup) }\end{array}$} \\
\hline & & Mean & SEM & Mean & SEM & Mean & SEM \\
\hline Chow & 14 & $46 \cdot 9$ & $1 \cdot 6$ & 610 & 21 & 1.52 & 0.09 \\
\hline Tristearin & 8 & $52 \cdot 1$ & $2 \cdot 9$ & $886^{* * *}$ & 50 & 1.53 & 0.05 \\
\hline PUFA & 6 & $41 \cdot 2$ & 1.9 & 700 & 32 & 1.73 & $0 \cdot 15$ \\
\hline Triolein & 9 & $38 \cdot 6^{* *}$ & $2 \cdot 1$ & 657 & 35 & $1 \cdot 70$ & 0.08 \\
\hline $\mathrm{MCT}$ & 21 & $31 \cdot 6^{* * *}$ & 1.0 & $537^{*}$ & 17 & $0.99 * * *$ & 0.06 \\
\hline
\end{tabular}

PUFA, polyunsaturated fatty acids; MCT, medium-chain triacylglycerols.

Mean values were significantly different from those for chow diet: ${ }^{*} P<0.05,{ }^{* *} P<0.01$, ${ }^{* * *} P<0.001$.

$\dagger$ For details of diets and procedures, see p. 780 .

pups compared with commercial chow. A similar synthetic diet containing peanut oil $(200 \mathrm{~g} / \mathrm{kg}$ diet; a mixture of oleic and linoleic acids) significantly increased pup growth compared with a fat-free or chow diet (Grigor \& Warren, 1980). It seems, therefore, that the observed inhibitory effect of MCT diet on pup weight gain is not a common property of diets with increased lipid content. The decrease in pup weight gain over the period of MCT feeding (approximately $40 \mathrm{~g}$ per litter) is higher than can be explained on the basis of decrease in food and energy intake alone (Table 1).

Addition of fat to the chow dilutes the content of other nutrients and it is possible that this may have effects in addition to those attributable to the increased lipid content. The finding that pup growth was unaffected by the diets containing LCT (Table 1) suggests that the dilution did not lead to a limitation of the supply of essential nutrients to the mothers.

\section{Tissue lipogenesis}

All the high-fat diets inhibited lipogenesis in vivo in the lactating mammary gland of fed rats (Table 2). The order of effectiveness of the diets was: PUFA ( $92 \%$ inhibition), triolein $(83 \%)$, tristearin $(76 \%)$ and MCT $(57 \%)$. The triolein diet also inhibited lipogenesis in liver, whereas the MCT diet increased the rate of hepatic lipogenesis approximately 3 -fold (Table 2). MCT had a similar stimulatory effect on lipogenesis in brown adipose tissue. Previous experiments from this laboratory have shown that an oral load of MCT oil given to fed lactating rats increases the rate of lipogenesis in liver and brown adipose tissue (Agius \& Williamson, 1980). The finding that in vivo feeding of MCT results in stimulation of liver lipogenesis but inhibition of mammary gland lipogenesis suggests either a fundamental difference in the regulation of the process in the two tissues and/or in the metabolism of medium-chain fatty acids. The medium-chain fatty acids are not directly converted to esterified products in liver, whereas they are not oxidized to any appreciable extent in mammary gland (Heesom et al. 1992).

The measurements of lipogenesis by Grigor \& Warren (1980) are not strictly comparable with the present work because their diets were semi-synthetic and the comparisons were made against a fat-free diet. However, it is of interest that they found no inhibition of mammary gland lipogenesis with a coconut oil diet (lauric acid, $\mathbf{C}_{12}$ ) when compared with a chow diet. Laurate does not inhibit the conversion of glucose to lipid in mammary gland acini in vitro, whereas octanoate and decanoate (major components of the triacylglycerols 


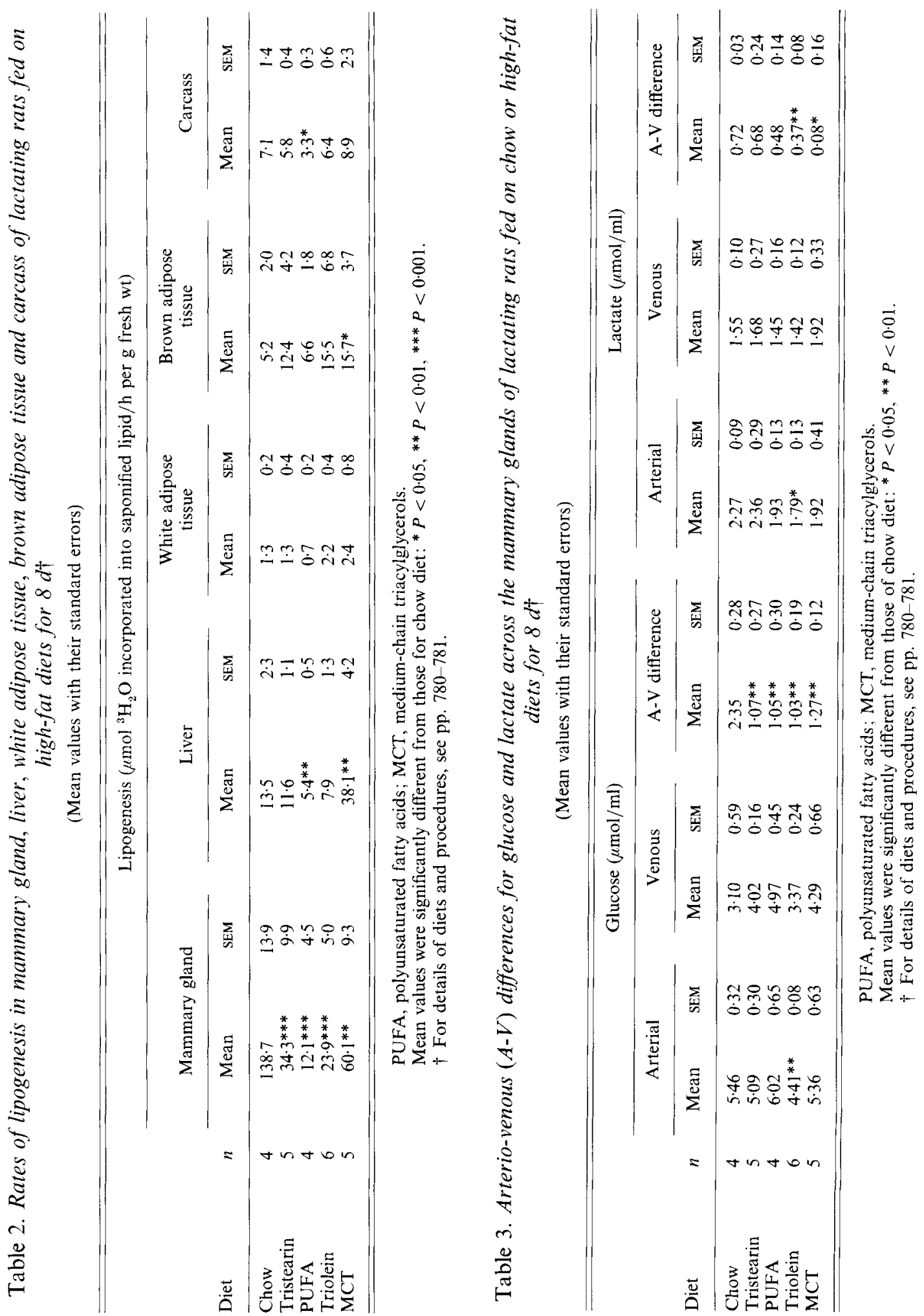


in the MCT oil) have a marked inhibitory effect (Heesom et al. 1992). Only the PUFA diet inhibited the rate of lipogenesis in the carcass (excluding liver, gastrointestinal tract and mammary gland; Table 2). The various diets had no effect on the low rate of white adipose tissue lipogenesis which is a characteristic of lactation in the rat (for reviews, see Williamson, 1980; Vernon \& Flint, 1983).

As would be expected from the decreased rate of lipogenesis, all the high-fat diets decreased the arterio-venous difference for glucose across the lactating gland (Table 3) and assuming that the blood flow was not altered to the gland this means that glucose extraction was decreased. Both the MCT and triolein diets also decreased the arterio-venous difference for lactate (Table 3). In vitro both octanoate and decanoate increase the proportion of glucose utilized which accumulates as lactate, suggesting inhibition of the pyruvate dehydrogenase (EC 1.2.4.1) step (Heesom et al. 1992).

The rate of lipogenesis in the lactating mammary gland of the rat shows a diurnal pattern which is highly correlated with food intake (Munday \& Williamson, 1983) and the depressed rate of lipogenesis in starved $(24 \mathrm{~h})$ lactating rats can be rapidly increased by refeeding a chow diet (Mercer \& Williamson, 1987). Consequently there is the possibility that in the present experiments the rates of lipogenesis were influenced by different eating patterns on the various diets. We have measured, therefore, the rates of lipogenesis (between 30 and 90 min postfeeding) in starved rats fed on a meal $(5 \mathrm{~g})$ of the previous diet (Table 4). Refeeding the chow meal increased the rate of lipogenesis in mammary gland approximately 10 -fold (Table 4). The PUFA and triolein meals caused significant inhibition of the stimulatory response to refeeding (78 and $71 \%$ inhibition respectively; Table 4 ). Both the tristearin and MCT meals gave lower stimulation of lipogenesis but the values were not significantly different from the chow meal. The MCT meal significantly increased the rate of lipogenesis in liver above the values for the chow meal (Table 4). Thus, the pattern of lipogenesis in the various tissues in response to the high-fat diets is similar irrespective of whether the rats are in the fed state (Table 2) or in the starved-refed state (Table 4).

\section{Metabolic fate of ${ }^{14} \mathrm{C}$-labelled lipid meal}

Feeding an MCT meal $(5 \mathrm{~g})$ containing $\left[1-{ }^{14} \mathrm{C}\right.$ ]octanoate (MCT oil contains $560 \mathrm{~g} \mathrm{C}_{8} / \mathrm{kg}$ ) to starved $(24 \mathrm{~h}$ ) lactating rats previously fed on the chow diet resulted in oxidation of $65 \%$ of the absorbed dose to ${ }^{14} \mathrm{CO}_{2}$ over $5 \mathrm{~h}$ (Table 5). The comparable value for a triolein meal containing $\left[1-{ }^{14} \mathrm{C}\right]$ triolein was $38 \%$. It is established that lactation results in the decreased oxidation and conservation for the mammary gland of $\left[1-{ }^{14} \mathrm{C}\right]$ triolein administered by oral intubation to fed rats, whereas no difference in the high rate of oral $\left[1-{ }^{14} \mathrm{C}\right]$ octanoate oxidation to ${ }^{14} \mathrm{CO}_{2}$ was observed between virgin and lactating rats (Oller do Nascimento $\&$ Williamson, 1986). Feeding the appropriate radioactive meal to rats previously fed on the triolein or MCT diets for 8-10d rather than chow did not result in any significant difference in the rate of ${ }^{14} \mathrm{CO}_{2}$ production from $\left[1-{ }^{14} \mathrm{C}\right]$ triolein or $\left[1-{ }^{14} \mathrm{C}\right]$ octanoate compared with the rats previously fed on chow (Table 5). In these experiments over $80 \%$ of the radioactivity in the meal was absorbed.

As expected from previous work from this laboratory (Oller do Nascimento \& Williamson, 1986), with a $\left[1-{ }^{14} \mathrm{C}\right]$ triolein load a high percentage of the absorbed radioactivity in the $\left[1-{ }^{14} \mathrm{C}\right]$ triolein meal was recovered as ${ }^{14} \mathrm{C}$-labelled lipid in the mammary gland (approximately $40 \%$ on a whole tissue basis) of rats previously fed on chow (Table 5). This value was not significantly altered in rats previously fed on the triolein diet. In contrast, little of the radioactivity in the $\left[1-{ }^{14} \mathrm{C}\right]$ octanoate meal accumulated as ${ }^{14} \mathrm{C}$-labelled lipid in the mammary gland (approximately 3-4\% on a whole tissue basis of rats previously fed on chow). Again, this value was not significantly different from that for rats previously fed on the MCT diet. Thus, the dietary MCT provides little $\mathrm{C}$ for the lactating mammary 


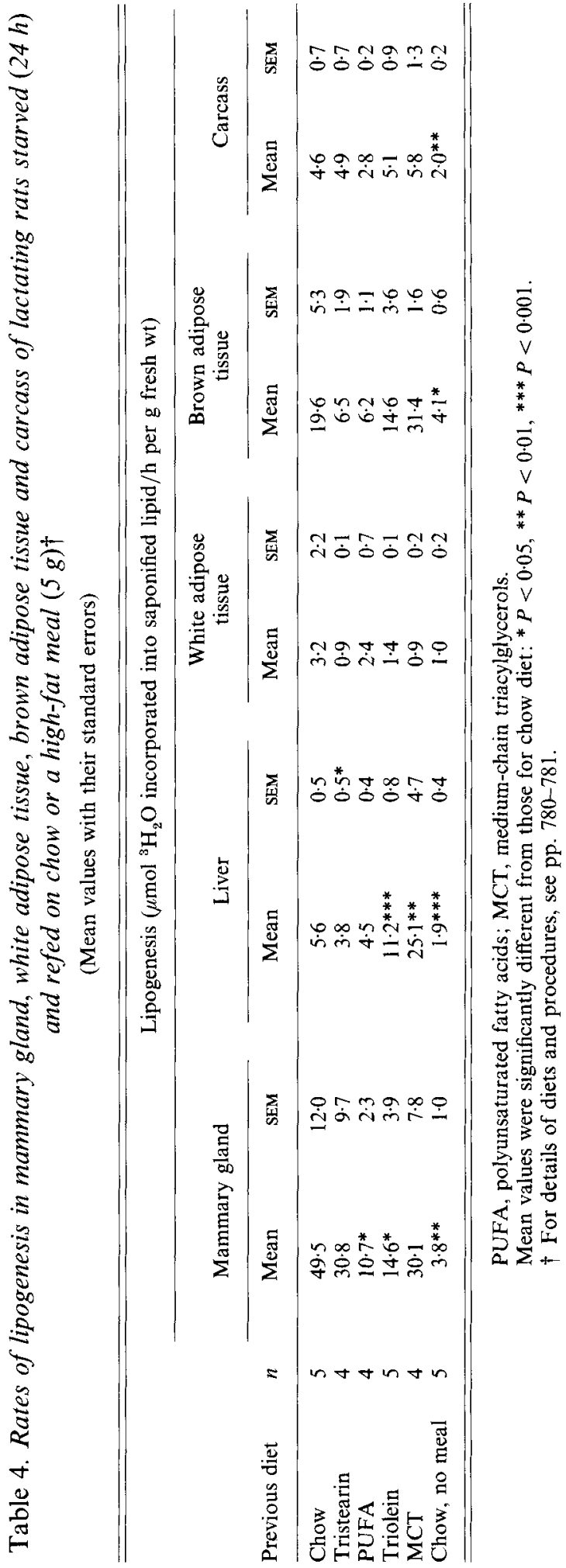


Table 5. ${ }^{14} \mathrm{CO}_{2}$ production and ${ }^{14} \mathrm{C}$-labelled lipid accumulation in tissues of lactating rats starved $(24 \mathrm{~h})$ and refed on a meal $(5 \mathrm{~g})$ containing $\left[1-{ }^{14} \mathrm{C}\right]$ triolein or $\left[1{ }^{14} \mathrm{C}\right]$ octanoate*

(Mean values with their standard errors)

\begin{tabular}{|c|c|c|c|c|c|c|c|c|c|c|}
\hline \multirow{3}{*}{$\begin{array}{l}\text { Previous } \\
\text { diet }\end{array}$} & \multirow[b]{3}{*}{ Meal } & \multirow[b]{3}{*}{$n$} & \multirow{2}{*}{\multicolumn{2}{|c|}{$\begin{array}{c}{ }^{14} \mathrm{CO}_{2} \\
\text { production } \\
\text { (\% absorbed } \\
\text { dose } / 5 \mathrm{~h})\end{array}$}} & \multicolumn{6}{|c|}{${ }^{14} \mathrm{C}$ labelled lipid ( $\%$ absorbed dose $/ 5 \mathrm{~h}$ per $\mathrm{g}$ tissue) } \\
\hline & & & & & \multicolumn{2}{|c|}{ Mammary gland } & \multicolumn{2}{|c|}{$\begin{array}{l}\text { White adipose } \\
\text { tissue }\end{array}$} & \multicolumn{2}{|c|}{$\begin{array}{c}\text { Brown adipose } \\
\text { tissue }\end{array}$} \\
\hline & & & Mean & SEM & Mean & SEM & Mean & SEM & Mean & SEM \\
\hline \multirow[t]{2}{*}{ Chow } & {$\left[1-^{14} \mathrm{C}\right]$ triolein } & 5 & $37 \cdot 8$ & $3 \cdot 1$ & $3 \cdot 23$ & $0 \cdot 33$ & $0 \cdot 042$ & 0.005 & 1.92 & $0 \cdot 7$ \\
\hline & {$\left[1-{ }^{14}\right.$ C]octanoate } & 5 & $65 \cdot 0$ & $1 \cdot 4$ & $0 \cdot 23$ & 0.03 & $0 \cdot 010$ & 0.002 & $0 \cdot 27$ & $0 \cdot 11$ \\
\hline Triolein & {$\left[1-{ }^{14} \mathrm{C}\right]$ triolein } & 6 & $32 \cdot 3$ & 40 & $2 \cdot 33$ & $0 \cdot 39$ & 0.088 & 0.034 & $3 \cdot 10$ & 1.5 \\
\hline MCT & {$\left[1-{ }^{14} \mathrm{C}\right]$ octanoate } & 4 & $59 \cdot 1$ & $3 \cdot 3$ & $0 \cdot 34$ & $0 \cdot 10$ & 0.022 & 0.007 & $0 \cdot 35$ & 0.07 \\
\hline
\end{tabular}

MCT, medium-chain triacylglycerols.

* For details of diets and procedures, see pp. 780-781.

gland and under the present experimental conditions there is no evidence for adaptation to the high-fat diets.

It may seem strange that so little of the $\left[1-{ }^{14} \mathrm{C}\right]$ octanoate accumulated in the mammary gland, particularly in view of the high rate of medium-chain fatty acid esterification in this tissue (Heesom et al. 1992) and the increased rate of hepatic lipogenesis on MCT diet. However, the high rate of medium-chain fatty acid oxidation (mainly in the liver) means that little reaches the peripheral circulation. The apparent high rate of lipogenesis in the liver as measured with ${ }^{3} \mathrm{H}_{2} \mathrm{O}$ only represents a small portion (less than $20 \%$; Gibbons, 1990) of the VLDL secreted by the liver and the ${ }^{3} \mathrm{H}_{2} \mathrm{O}$ method provides no information as to whether acetyl-CoA derived from octanoate is the source of $\mathrm{C}$ for the increased lipogenesis.

\section{Conclusions}

The decreased pup growth on the MCT diet suggests poor lactational performance and would appear to be due to at least two causes. First, the decreased dietary intake which is low compared with chow-fed rats even if expressed in terms of energy. Second, the inhibition of lipogenesis in the mammary gland which is not compensated for by uptake of the dietary MCT and, thus, there is a deficit of precursors for milk lipid synthesis. In the case of the LCT diets the inhibition of mammary gland lipogenesis can be viewed as a physiological response to conserve carbohydrate and presumably any deficit of precursors for milk lipid synthesis is made up by extraction by the gland of NEFA contained in chylomicrons derived from the dietary lipid. The present experiments provide no direct evidence on the mechanisms for the decreased dietary intake on the MCT diet nor for the inhibition of mammary gland lipogenesis. With regard to the latter a key question is whether sufficient of the medium-chain fatty acids (particularly octanoate) derived from the dietary MCT escape metabolism in the liver and reach the peripheral circulation for uptake by the gland and subsequent inhibition of glucose conversion to lipid (Heesom et al. 1992).

The authors wish to thank Mrs M. Barber for preparation of the manuscript and Mrs V. Ilic for skilled assistance. P.F.A.S. was a CAPES (Brazil) and ORS Scholar and D.H.W. is a member of the MRC External Scientific Staff. 


\section{REFERENCES}

Agius, L. \& Williamson, D. H. (1980). Rapid inhibition of lipogenesis in vitro in lactating rat mammary gland by medium- or long-chain triacylglycerols and partial reversal by insulin. Biochemical Journal 192, 361-364.

Baba, N., Bracco, E. F. \& Hashim, S. A. (1982). Enhanced thermogenesis and diminished deposition of fat in response to overfeeding with diet containing medium-chain triglyceride. American Journal of Clinical Nutrition $35,678-682$.

Bach, A. C. \& Babayan, V. K. (1982). Medium chain triglycerides: an update. American Journal of Clinical Nutrition 36, 950-962.

Bauman, D. E. \& Davis, C. L. (1974). Biosynthesis of milk fat. In Lactation, A Comprehensive Treatise, vol. 2, pp. 31-75 [B. L. Larson and V. R. Smith, editors]. New York: Academic Press

Geliebter, A., Torbay, N., Bracco, E. F., Hashim, S. A. \& Van Itallie, T. B. (1983). Overfeeding with mediumchain triglyceride diet results in diminished deposition of fat. American Journal of Clinical Nutrition 37, 1-4.

Gibbons, G. F. (1990). Assembly and secretion of hepatic very-low-density lipoprotein. Biochemical Journal $\mathbf{2 6 8}$, $1-13$.

Greenberger, N. J. \& Silkman, T. G. (1969). Medium-chain triglycerides - physiologic considerations and clinical implications. New England Journal of Medicine 280, 1045-1058.

Grigor, M. R. \& Warren, S. M. (1980). Dietary regulation of mammary lipogenesis in lactating rats. Biochemical Journal 188, 61-65.

Hamilton, J.D., Webb, J. P. \& Dawson, A. M. (1969). The absorption of tristearin and stearic acid and tripalmitin and palmitic acid. Studies on the rate-limiting steps in rats. Biochimica et Biophysica Acta 176, $27-36$.

Heesom, K. J., Souza, P. F. A., Ilic, V. \& Williamson, D. H. (1992). Chain-length dependency of interactions of medium-chain fatty acids with glucose metabolism in acini isolated from lactating rat mammary glands. A putative feed-back to control milk lipid synthesis from glucose. Biochemical Journal 281, 273-278.

Hohorst, H. J. (1963). L-(+)-Lactate. Determination with lactate dehydrogenase and DPN. In Methods of Enzymatic Analysis, pp. 266-270 [H. U. Bergmeyer, editor]. New York and London: Academic Press.

Katz, J., Wals, P. A. \& Van de Velde, R. L. (1974). Lipogenesis by acini from mammary gland of lactating rats. Journal of Biological Chemistry 249, 7348-7357.

Libertini, L. J. \& Smith, S. (1978). Purification and properties of a thioesterase from lactating mammary gland which modifies the product specificity of fatty acid synthesis. Journal of Biological Chemistry 253, 1393-1401.

Mercer, S. W. \& Williamson, D. H. (1987). The regulation of lipogenesis in vivo in the lactating mammary gland of the rat during the starved-refed transition. Studies with acarbose, a glucosidase inhibitor. Biochemical Journal 242, 235-243.

Munday, M. R. \& Williamson, D. H. (1983). Diurnal variations in food intake and in lipogenesis in mammary gland and liver of lactating rats. Biochemical Journal 214, 183-187.

Oller do Nascimento, C. M. \& Williamson, D. H. (1986). Evidence for conservation of dietary lipid in the rat during lactation and the immediate period after removal of the litter. Decreased oxidation of oral $\left[1-{ }^{14} \mathrm{C}\right] \mathrm{triolein}$. Biochemical Journal 239, 233-236.

Robinson, A. M., Girard, J. R. \& Williamson, D. H. (1978). Evidence for a role of insulin in the regulation of lipogenesis in lactating rat mammary gland. Measurements of lipogenesis in vivo and plasma hormone concentrations in response to starvation and refeeding. Biochemical Journal 176, 343-346.

Robinson, A. M.\& Williamson, D. H. (1977). Comparison of glucose metabolism in the lactating mammary gland of the rat in vivo and in vitro. Effects of starvation, prolactin or insulin deficiency. Biochemical Journal 164, $153-159$.

Scharrer, E. \& Langhans, W. (1990). Mechanisms for the effect of body fat on food intake. International Monographs in Nutrition, Metabolism and Obesity 1, 63-86.

Slein, M. W. (1963). D-Glucose. In Methods of Enzymatic Analysis, pp. 117-123 [H. U. Bergmeyer, editor]. New York and London: Academic Press.

Souza, P. F. A. \& Williamson, D. H. (1990). Differential effects of dietary fatty acid saturation and chain length on lipogenesis in liver and mammary gland of lactating rats. Proceedings of the Nutrition Society 49, 3A.

Souza, P. F. A. \& Williamson, D. H. (1991). Effects of long-term feeding of high fat diets containing triolein or medium-chain triacylglycerols to lactating rats on the disposal of a meal containing the ${ }^{14} \mathrm{C}$-labelled lipid. Proceedings of the Nutrition Society 50,7A.

Stansbie, D., Brownsey, R. W., Crettaz, M. \& Denton, R. M. (1976). Acute effects in vivo of anti-insulin serum on rates of fatty acid synthesis and activities of acetyl-coenzyme $A$ carboxylase and pyruvate dehydrogenase in liver and epididymal adipose tissue of fed rats. Biochemical Journal 160, 413-416.

Tso, P. \& Balint, J.A. (1986). Formation and transport of chylomicrons by enterocytes to the lymphatics. American Journal of Physiology 250, G715-G726.

Vernon, R. G. \& Flint, D. J. (1983). Control of fatty acid synthesis in lactation. Proceedings of the Nutrition Society 42, 315-331.

Wallenstein, S., Zucker, C. L. \& Fleiss, J. L. (1980). Some statistical methods useful in circulation research. Circulation Research 47, 1-9.

Williamson, D. H. (1980). Integration of metabolism in tissues of the lactating rat. FEBS Letters 117, Suppl., K93-K 105 . 